\title{
HEALTHCARE-ASSOCIATED INFECTION IN NEUROSURGICAL PATIENTS IN UKRAINE: RESULTS OF A MULTICENTER STUDY (2017-2019)
}

DOI: 10.36740/WLek202108129

\author{
Aidyn G. Salmanov ${ }^{1,2}$, Dmytro V. Shchehlov³ , Oleh Svyrydiuk ${ }^{3}$ Ihor M. Bortnik ${ }^{3}$, Maryna Mamonova ${ }^{4}$, \\ Yaroslav Kudelskyi ${ }^{3}$, Farida H. Rzayeva ${ }^{1}$ \\ 'SHUPYK NATIONAL HEALTHCARE UNIVERSITY OF UKRAINE, KYIV, UKRAINE \\ ¿UKRAINIAN ASSOCIATION OF INFECTION CONTROL AND ANTIMICROBIAL RESISTANCE, KYIV, UKRAINE \\ ${ }_{3}^{3 S C I E N T I F I C-P R A C T I C A L ~ C E N T E R ~ O F ~ E N D O V A S C U L A R ~ N E U R O R A D I O L O G Y ~ O F ~ N A T I O N A L ~ A C A D E M Y ~ O F ~ M E D I C A L ~ S C I E N C E S ~ O F ~ U K R A I N E, ~ K Y I V, ~ U K R A I N E ~}$ \\ ${ }^{4 B O G O M O L E T S ~ N A T I O N A L ~ M E D I C A L ~ U N I V E R S I T Y, ~ K Y I V, ~ U K R A I N E ~}$
}

\begin{abstract}
The aim: To obtain the estimates of the current prevalence of healthcare-associated infection among neurosurgical patients and determine the antimicrobial resistance of responsible pathogens in Ukraine.

Materials and methods: We performed a retrospective multicenter cohort study was based on surveillance data of HAls among neurosurgical patients from 2017 to 2019 in 7 regional hospitals. Definitions of HAI were used from the CDC/ NHSN.

Results: 0 f 9,711 neurosurgical patients, 1,031 (20.9\%) HAls were observed. The most frequently of HAl types were surgical site infection (53.2\%), pneumonia (17.3\%), urinary tract infection (15.1\%) and bloodstream infection (14.4\%). The overall prevalence of HAls was $20.9 \%$ within three months and was $12.8 \%$ during one month surveillance period. Death during hospitalization was reported in $11.3 \%$ of HAl cases. Escherichia coli were most commonly reported, accounting for $24.3 \%$ of all organisms, followed by Staphylococcus aureus (15.9\%), Enterococcus spp (14.6\%), Pseudomonas aeruginosa (13.4\%), and Klebsiella pneumoniae (9.8\%). Meticillin resistance was $34.6 \%$ of S.aureus isolates. Vancomycin resistance was in $7.1 \%$ of isolated enterococci. Among the gram-negative bacteria, third-generation cephalosporins resistance was found in $48.5 \%$ of K.pneumoniae and in $34.3 \%$ of $E$. coli isolates. Carbapenem resistance was reported in $11.7 \%$ of all included Enterobacteriaceae, also highest in K.pneumoniae, and in $32.4 \%$ of P.aeruginosa isolates and in $67.2 \%$ of Acinetobacter spp. isolates.

Conclusions: Healthcare-associated infections are a cause for mortality and morbidity among hospitalized neurosurgical patients. This is due to increase emergence of antimicrobial-resistant pathogens. Routinely collected surveillance data are of great value as a basis for studying the consequences of HAls.
\end{abstract}

KEY WORDS: Neurosurgery, healthcare-associated infection, prevalence, mortality, antimicrobial resistance

Wiad Lek. 2021;74(8):1945-1951

\section{INTRODUCTION}

Healthcare-associated infections (HAIs) have been recognized as one of the most important public health problems in the world [1]. The effects to both human and financial costs from of these infections are high [2]. Patients admitted in neurosurgical units are at higher risk of developing one or more infections due to severity of the underlying illness, impaired protective reflexes, increased utilization of invasive medical devices, increased duration of hospital stay [3]. Healthcare-associated infections remain a cause for morbidity $[4,5]$ and mortality [5-7] among hospitalized patient.

HAI is a difficult issue and a key point in the diagnosis and treatment of neurosurgery; it is also an important factor affecting effective treatment and patient prognosis. Improvement in infection control methods, surgical technique, and availability of antimicrobial prophylaxis showed advanced infection control, but it seems impossible to drastically reduce the number of healthcare-associated infections among patients. Prevention and control of infection is the cornerstone of patient safety procedures [8]. A most number of studies have confirmed that interventions using evidence-based strategies can prevent the occurrence of HAI [9]. Over the past one decades, along with significant improvements in clinical care in many countries, the incidence rate of HAIs among neurosurgery patients remains an important issue.

Pathogens associated with these infections are often Multi-Drug Resistant (MDR) due to selective antibiotic pressure [10]. Current guidelines recommend the use of antibiotics as well for prevention, and as for both treatment HAIs. Empiric antibiotic therapy should broadly cover the most likely pathogens involved, unless a causative agent has already been isolated. However, the growing antimicrobial resistance is limiting their use. Antimicrobial resistance pathogens caused HAIs is becoming more and 
more pressing for medical specialists a worldwide. In the available literature, studies on antimicrobial resistance of HAI agents in neurosurgery are limited.

Surveillance for HAIs is an essential element so as to know the current prevalence of the condition, to identify potential risk factors and to implement various preventive strategies. However, there is no surveillance system for HAI in Ukraine. Consequently, incidence rates of HAIs among neurosurgical patients and antimicrobial resistance in Ukraine are currently unknown. This creates problems as well for physicians and as infection control professionals in Ukraine. The prevalence of and causative agents of most HAIs among neurosurgical patients have not been studies in Ukraine. This was the basis for our study.

\section{THE AIM}

To obtain the first estimates of the current prevalence of healthcare-associated infections after neurosurgical procedures and determine the antimicrobial resistance of responsible pathogens in Ukraine.

\section{MATERIALS AND METHODS}

\section{SETTING AND PARTICIPANTS}

We performed a retrospective multicenter cohort study was based on surveillance data of healthcare-associated infections. This study included patients undergoing a neurosurgical procedure in 7 regional hospitals of Ukraine from January 1st, 2017 to December 31st, 2019. Total these hospitals for neurosurgical patients had 210 beds. The hospitals are similar in terms of medical equipment, staff and number of beds. All hospitals were required to have at least one full-time infection-control professional and clinical microbiology laboratory. Only hospitals that provided data for at least three years were included in the study.

In the current study, we included 9734 patients. All patients were local residents. However, 23 of these were excluded from this study. Patients who were aged 18 years or older and underwent elective or emergency craniotomy and survived at least 7 days after surgery were included in the study. Exclusion criteria were antibiotic use within one month prior to hospitalization. Patients highly suspicious of central nervous infection prior to the neurosurgical procedure, patients who underwent reoperation and patients who passed away within 48 hours after surgery, or did not have the incision site closed also were excluded.

\section{DEFINITION}

We used the Centers for Disease Control and Prevention/ National Healthcare Safety Network (CDC/NHSN) Surveillance Definition of Healthcare-associated infection and criteria for Specific Types of Infections [11].Infections occurring at more than one site in the same patient were reported as two separate infection episodes. The criteria used to define SSI were established by the CDC in 2017
$[12,13]$. In accordance with these criteria, SSI was defined as any infection occurring within 1 month of the operation when no prosthetic material was left in the wound, or within 1 year when prosthetic material remained within the operation site. However, since the monitoring period was 90 days, SSI was evaluated as an infection within 90 days even if the prosthetic material was inserted. In this study SSIs were classified depending on the degree of infection as follows: superficial incisional, deep incisional, and organ/space. Because no clear distinction exists between superficial and deep incisional infection in brain surgery, we included skin or subcutaneous tissue in the definition of superficial incisional infection, and fascia/muscle layers and aponeurosis/skull bone in that of deep incisional infection. Organ/space infection was diagnosed as infection of the central nervous system, such as intracranial infection (brain abscess, subdural or epidural infection, encephalitis), and meningitis or ventriculitis [13].

\section{DATA COLLECTION}

We collected the data using structured CDC/NHSN Checklist. Cases of HAIs that met standard case definitions were identified through active follow up during the hospital stay, on return to hospital, and during visits to ambulatory. In this study the surveillance period for the patients after neurosurgical procedure was 30 days, and monitoring period was 90 days, when prosthetic material remained within the operation site; those discharged or transferred were monitored at outpatient clinics.

\section{MICROBIOLOGICAL METHODS}

All samples were obtained from patients with clinical symptoms of HAI. Microbial isolates were identified using standard microbiological techniques. Antibiotic susceptibility testing was performed by using the disk diffusion method according to the recommendations of the European Committee on Antimicrobial Susceptibility Testing (EUCAST). Strains in the intermediate range were classified as resistant for data analysis.

\section{ETHICS}

The Shupyk National Healthcare University of Ukraine Ethics Committee approved this study and the waiver of informed consent to participate in this study due to its retrospective design. To protect the privacy of the patients, the study excluded sensitive patient identifiers. All participants data were anonymised prior to the analysis.

\section{STATISTICAL ANALYSIS}

The analysis of statistical data was performed using Excel. Prevalence of HAIs after neurosurgical procedure was reported as the percentage of the total number of patients who had surgical procedure. Data were expressed as mean \pm standard deviation and median. All variables that were found to be linked to HAI at a $25 \%$ level of significance 
Table I. Prevalence of HAls among 9711 neurosurgical patients in Ukrainian hospitals, 2017-2019

\begin{tabular}{ccc}
\hline Type of HAI & No. of HAls & \% (95\% CI) \\
\hline All infections & 2031 & $20.9(20.5-21.3)$ \\
\hline SSI & 1080 & $11.1(10.8-11.4)$ \\
\hline PNEU & 352 & $3.6(3.4-3.8)$ \\
\hline UTI & 307 & $3.2(3.0-3.4)$ \\
\hline BSI & 292 & $3.0(2.8-3.2)$ \\
\hline
\end{tabular}

HAI, healthcare-associated infection; SSI, surgical site infection; PNEU, pneumonia; UTI, urinary tract infection; BSI, bloodstream infection; Cl, confidence interval;

Table II. Characteristics of neurosurgical patients with HAls treated in Ukrainian hospitals, 2017-2019

\begin{tabular}{|c|c|c|c|c|}
\hline \multirow{2}{*}{ Characteristics } & \multirow{2}{*}{$\begin{array}{c}\text { All patients } \\
\text { n (\%) }\end{array}$} & \multicolumn{2}{|c|}{ HAls } & \multirow{2}{*}{ P value* } \\
\hline & & Yes n (\%) & No n (\%) & \\
\hline All & $9711(100)$ & $2,031(20.9)$ & $7,680(79,1)$ & \\
\hline \multicolumn{5}{|l|}{ Gender } \\
\hline Men & 4652 (47.9) & $1133(55.8)$ & $2149(47.2)$ & \\
\hline Women & $5059(52.1)$ & $898(44.2)$ & $2721(52.8)$ & \\
\hline Age (y) & & & & $<0.001$ \\
\hline $20-35$ & $1057(10.9)$ & $74(3.6)$ & $912(11.9)$ & \\
\hline $36-50$ & $1228(12.6)$ & $125(6.2)$ & $1038(13.5)$ & \\
\hline $51-65$ & $1671(17.2)$ & $254(12.5)$ & $1356(17.7)$ & \\
\hline $60-81$ & 3047 (31.4) & $725(35.7)$ & $2361(30.7)$ & \\
\hline$\geq 82$ & $2708(27.9)$ & $853(42.0)$ & $2013(26.2)$ & \\
\hline Admission type & & & & $<0.001$ \\
\hline Acute & $6047(62.3)$ & $1382(68.0)$ & $4705(61.3)$ & \\
\hline Elective & $3664(37.7)$ & $649(32.0)$ & $2975(38.7)$ & \\
\hline Pre-prevalence period $(\mathrm{d})^{* *}$ & & & & $<0.001$ \\
\hline 2 & $2585(26.6)$ & $182(9.0)$ & $2221(28.9)$ & \\
\hline $3-5$ & $2267(23.3)$ & $301(14.8)$ & $1876(24.4)$ & \\
\hline $6-8$ & $2054(21.2)$ & $469(23.1)$ & $1615(21.0)$ & \\
\hline $9-11$ & $1147(11.8)$ & $367(18.1)$ & $842(11.0)$ & \\
\hline $12-15$ & $1131(11.6)$ & $438(21.6)$ & $788(10.3)$ & \\
\hline$>15$ & $527(5.4)$ & $276(13.6)$ & $339(4.4)$ & \\
\hline Charlson comorbidity index & & & & $<0.001$ \\
\hline 0 & $4881(50.3)$ & $683(33.6)$ & $3987(51.9)$ & \\
\hline 1 & $1722(17.7)$ & $417(20.5)$ & $1340(17.4)$ & \\
\hline 2 & $1611(16.6)$ & $499(24.6)$ & $1222(15.9)$ & \\
\hline 3 & $568(5.8)$ & $206(10.1)$ & $417(5.4)$ & \\
\hline 4 & $225(2.3)$ & $51(2.5)$ & $168(2.2)$ & \\
\hline$>4$ & $704(7.3)$ & $175(8.6)$ & $546(7.1)$ & \\
\hline
\end{tabular}

HAls, health care-associated infections.

*Performed by the X2 test

**Time from hospital admission to study inclusion

were included in the analysis, and then the 95\% CI were calculated. The association between categorical variables was assessed by Chi-square/Fisher-exact test. Continuous variables such as infected and non-infected were compared by Wilcoxon rank-sum test. All $P$ values were two-sided, and a $P$ value of less than 0.05 was considered significant.

\section{RESULTS}

\section{PREVALENCE OF HAI}

Of 9,711 patients undergoing neurosurgical procedure included in the study, 2,031 patients had HAIs and 7,680 did not have HAIs. The most frequently reported HAI 
Table III. Mortality in neurosurgical patients with HAls in Ukrainian hospitals, 2017-2019

\begin{tabular}{cccc}
\hline \multirow{2}{*}{ Type of infection } & Infections & \multicolumn{2}{c}{ Mortality } \\
\cline { 3 - 4 } & $\mathbf{( n )}$ & $\mathbf{n}$ (\%) & $\mathbf{9 5 \%} \mathbf{C l}$ \\
\hline All infections & 2031 & $229(11.3)$ & $10.6-12.0$. \\
\hline SSI & 1080 & $202(18.7)$ & $17.8-19.6$ \\
\hline PNEU & 352 & $12(3.4)$ & $3.0-3.8$ \\
\hline UTI & 307 & $4(1.3)$ & $1.1-1.6$ \\
\hline BSI & 292 & $11(3.8)$ & $3.4-4.2$ \\
\hline
\end{tabular}

BSI, bloodstream infection; HAI, healthcare - associated infection; PNEU, pneumonia ; SSI, surgical site infection; UTI, urinary tract infection.

Table IV. Pathogens isolated from the neurosurgical patients during surveillance for HAls in Ukrainian hospitals, 2017-2019

\begin{tabular}{|c|c|c|c|c|c|}
\hline \multirow[b]{2}{*}{ Microorganism } & \multicolumn{5}{|c|}{ Organisms reported (\%) } \\
\hline & $\begin{array}{c}\text { All HAI } \\
(n=2,089)\end{array}$ & $\begin{array}{c}\text { SSI } \\
(n=1122) \\
\end{array}$ & $\begin{array}{c}\text { PNEU } \\
(n=359)\end{array}$ & $\begin{array}{c}\text { BSI } \\
(n=297) \\
\end{array}$ & $\begin{array}{c}\text { UTI } \\
(n=311)\end{array}$ \\
\hline Escherichia coli & 24,3 & 21,1 & 6,8 & 3,9 & 18,2 \\
\hline Staphylococcus aureus & 15,9 & 25,1 & 13,9 & 10,8 & 5,4 \\
\hline Enterococcus spp & 14,6 & 15,7 & 2,1 & 5,9 & 9,9 \\
\hline Pseudomonas aeruginosa & 13,4 & 11,3 & 17,6 & 6,2 & 16,7 \\
\hline Klebsiella pneumoniae & 9,8 & 5,3 & 24,9 & 24,3 & 15,6 \\
\hline Coagulase-negative staphylococci & 5,3 & 6,2 & 0,3 & 16,5 & 2,2 \\
\hline Candida spp & 5,1 & 4,2 & 0,6 & 8,4 & 6,3 \\
\hline Acinetobacter spp & 4,9 & 3,5 & 26,3 & 12,6 & 4,1 \\
\hline Enterobacter spp & 3,3 & 4,2 & 2,7 & 3,2 & 6,8 \\
\hline Proteus spp & 2,3 & 2,1 & 1,7 & 1,1 & 7,7 \\
\hline Other* & 1,1 & 1,3 & 3,1 & 7,1 & 7,1 \\
\hline
\end{tabular}

BSI, bloodstream infection; HAI, healthcare-associated infection; PNEU, pneumonia; SSI, surgical site infection; UTI, urinary tract infection.

* "Other" includes 7 different organisms.

types were SSIs (53.2\%), PNEU (17.3\%), UTIs (15.1\%) and BSIs (14.4\%).

The overall prevalence of HAIs was $20.9 \%$ within three months and were $12.8 \%$ during one month surveillance period. Our study showed that the prevalence of HAI among patients was higher during the three-month follow-up period than in the one-month study ( $20.9 \%$ versus $12.8 \%)$. The most frequently identified types of HAIs was the following: SSI, $11.1 \%$ (95\% confidence interval [CI], 10.8-11.4), PNEU, 3.6\% (95\% CI, 3.4-3.8), UTI, 3.2\% (95\% CI, 3.0-3.4), and BSI, 3.0\% (95\% CI, 2.8-3.2) (Table I). This study showed that the incidence of HAI in neurosurgical patients was higher in 2019 than in 2017 (20.9\% vs. 14.3\%).

An overview of the analyzed variables is shown in Table II. The mean age of the 9711 patients was $52.8 \pm 17.3$ years (range, $18-86$ years), and 2503 (47.9\%) were male and 5059 (52.1\%) were women. The overall prevalence was higher in men than in women (11.7\% vs $9.2 \%)$ and increased with age. The mean age of the patients with and without HAI was 46.1 years and 53.8 years, respectively, and the difference was statistically significant $(p<0.001)$. For the oldest patients ( $\geq 82$ years old), we found a prevalence of $16.7 \%$ versus $3.8 \%$ for the patients 20 -35 years. Acute admission patients had a higher prevalence of HAIs than those with elective admission, $12.4 \%$ and $9.5 \%$, respectively. We found an association between hospital stay before the date of prevalence study and the prevalence of HAIs. Charlson comorbidity index up to 3 was associated with a higher prevalence of HAI, whereas patients with a Charlson comorbidity index 4 or higher had a lower prevalence (Table II).

\section{MORTALITY}

In this study of the HAI case-patients identified, 229 (11.3\%) died before discharge. We found that mortality was higher among men than women, whereas mortality increased with age for both men and women. Patients with acute admission to the hospital had higher mortality than patients with elective admission. A high Charlson comorbidity index also gave increased mortality. Following adjustment for confounding factors, we found that patients with HAIs had a significantly increased mortality risk compared to patients without HAIs. The highest mortality risk was observed in patients with SSI and BSI, followed by patients with PNEU. No increased risk of death was found in patients with UTI (Table III).

\section{RESPONSIBLE PATHOGENS AND ANTIMICROBIAL RESISTANCE}

A total of 2,089 pathogenic microorganisms were isolated from the neurosurgical patients with HAIs (Table IV). 
Considering all HAI types together, Escherichia coli were most commonly reported, accounting for $24.3 \%$ of all organisms, followed by Staphylococcus aureus (15.9\% of all organisms), Enterococcus spp (14.6\% of all organisms), Pseudomonas aeruginosa ( $13.4 \%$ of all organisms), and Klebsiella pneumoniae ( $9.8 \%$ of all organisms). These were the same organisms reported most commonly for SSI cases. For PNEU, Acinetobacter spp. were most commonly reported, accounting for $26.3 \%$ of all organisms, followed by K. pneumoniae (24.9\% of all organisms) and P. aeruginosa (17.6\% of all organisms). For BSI, K.pneumoniae were most commonly reported ( $24.3 \%$ of all organisms), followed by coagulase-negative staphylococci $(16.5 \%$ of all organisms), Acinetobacter spp (12.6\% of all organisms) and S. aureus ( $10.8 \%$ of all organisms). E. coli ( $18.2 \%$ of all organisms), P. aeruginosa (16.7\% of all organisms), and $K$. pneumoniae (15.6\% of all organisms) were most common pathogens causing UTIs.

Antimicrobial resistance in the isolates associated with HAIs showed, among the gram-positive bacteria, that $39.7 \%$ and $5,2 \%$ of coagulase-negative staphylococci isolates were b-lactam (oxacillin) - and glycopeptides (teicoplanin)-resistant, respectively. Meticillin resistance was reported in $34.6 \%$ of S.aureus isolates. Vancomycin resistance was reported in $7.1 \%$ of isolated enterococci. Among the gram-negative bacteria, third-generation cephalosporins (cefotaxime or ceftazidime) resistance was found in $48.5 \%$ of K.pneumoniae and in $34.3 \%$ of E,coli isolates. Carbapenem resistance was reported in $11.7 \%$ of all included Enterobacteriaceae, also highest in K.pneumoniae, and in $32.4 \%$ of P.aeruginosa isolates and in $67.2 \%$ of Acinetobacter spp. isolates.

\section{DISCUSSION}

To our knowledge, this study was the first attempt to assess the overall burden of HAIs in neurosurgical patients at the hospitals in Ukraine. We estimate that HAIs in neurosurgical patients in Ukrainian hospitals are encountered with an average prevalence of $20.9 \%$, and the prevalence of the 4 most frequently recorded types of infections was for the following: SSI, $11.1 \%$, PNEU, 3.6\%, BSI, 3.0\%, and UTI, $3.2 \%$. Our study showed that the prevalence of HAI among patients was higher during the three-month follow-up period than in the one-month study (20.9\% versus $12.8 \%)$. Of all reported HAIs, the most frequently reported HAI types were SSIs (53.2\%), PNEU (17.3\%), UTIs (15.1\%) and BSIs (14.4\%). Of the HAI case-patients identified, $11.3 \%$ died before discharge. We found that patients with HAIs had a significantly increased mortality risk compared with patients without HAIs. The highest mortality risk was observed in patients with SSI and BSI, followed by patients with PNEU. No increased risk of death was found in patients with UTI. A high Charlson comorbidity index also gave increased mortality.

Few comparable studies of the burden of HAIs in neurosurgical patients have been performed to date, with most conducted at the regional or single-center level. Most studies assessing the impact of HAIs have been primarily conducted in ICUs or have focused on a single type of HAI. According this studies HAIs for patients admitted to the neuro-ICU, the rate of HAIs reaches up to $36-40 \%$ when admitted for more than $48 \mathrm{~h}[14,15]$. The neuro-ICU patient is particularly vulnerable to pneumonias, due to the high rate of dysphagia and risk of aspiration in patients with neurological diseases [14].

Comparison of results between different studies remains difficult primarily because of differences in patient-case mix and methodology. Previous studies found that the incidence of HAI in non-Ukraine neurosurgical hospitals was from 1.3-11.1\% [16-22], although data are heterogeneous due to use of different definitions for infections, and variable exclusion of culture-negative results, making a true estimate of prevalence difficult. In our study, the overall prevalence of neurosurgical patients with HAI was $20.9 \%$. Only a few studies have estimated the impact of HAIs on mortality in hospital settings. According to the literature, mortality in neurosurgical patients with HAI ranges from $3.5 \%$ to $12 \%[5-7,23]$. In our study death during hospitalization was reported in $11.3 \%$ of HAI cases.

Microbiological monitoring of the prevalence of etiologic agents of HAIs in neurosurgical patients and antimicrobial resistance is necessary to enhance our knowledge of its epidemiology. In our study E. coli were most commonly reported, accounting for $24.3 \%$ of all organisms, followed by S. aureus (15.9\%), Enterococcus spp (14.6\%), P. aeruginosa (13.4\%), and K. pneumoniae (9.8\%). Meticillin resistance was $34.6 \%$ of S.aureus isolates. Vancomycin resistance was in $7.1 \%$ of isolated enterococci. Among the gram-negative bacteria, third-generation cephalosporins resistance was found in $48.5 \%$ of K.pneumoniae and in $34.3 \%$ of E. coli isolates. Carbapenem resistance was reported in $11.7 \%$ of all included Enterobacteriaceae, also highest in K.pneumoniae, and in $32.4 \%$ of P.aeruginosa isolates and in $67.2 \%$ of Acinetobacter spp. isolates.

Our study showed a highs incidence of HAI and mortality among patients admitted in the neurosurgery unit in Ukrainian hospitals. It might be either due to low adherence to the preventive measures of infection control and highs antimicrobial resistance. However, to evaluate the efficacy of preventive measures, periodic surveillance for HAI over a longer period is warranted.

Our study showed the incidence HAIs in neurosurgical patients in Ukrainian hospitals has increased over the last three years, and it provided an evidence of the necessity for infection control in surgical site infection, pneumonia, bloodstream infections, and urinary tract infections. The necessity for improved infection control measures related to HAIs. Surveillance data are of great value as a basis for development infection control program.

\section{STUDY LIMITATIONS}

The absence of national surveillance data in Ukraine compelled us to rely entirely on data from the only retrospective multicenter prevalence survey to assess the bur- 
den of HAIs in neurosurgical patients. The present study is first step is to quantify this burden for the first time and estimate of the incidence of HAI in neurosurgical patients in Ukraine. The strengths of the study lie in the application of CDC/NHSN methodology for surveillance. A limitation of the study is that it only include 7 (29.2\%) from 24 regional hospitals in Ukraine. The results this study may not be representative of other regional hospitals of Ukraine with different distributions of incidence rate of HAIs in neurosurgical patients and antimicrobial resistance of causing pathogens.

\section{CONCLUSIONS}

Healthcare-associated infections are a cause for mortality and morbidity among hospitalized neurosurgical patients in Ukraine. The results of this study revealed high rates of HAIs after neurosurgical procedures, and most causing pathogens were associated with resistant to antibiotic strains. Routinely collected surveillance data provide thereby allowing for useful comparison for similar specialized units. This data is essential to develop targeted strategies to surveillance and reduce the incidence of HAI in neurosurgical patients.

\section{REFERENCES}

1. Allegranzi B., Nejad S.B., Combescure C. et al. Burden of endemic healthcare-associated infection in developing countries: systematic review and meta-analysis. Lancet. 2011;377(9761):228-241. doi: 10.1016/ S0140-6736(10)61458-4.

2. Plowman R. The socioeconomic burden of hospital acquired infection. Euro Surveill. 2000;5(4):49-50. doi: 10.2807/esm.05.04.00004-en.

3. Dettenkofer M., Ebner W., Hans F.J. et al. Nosocomial infections in a neurosurgery intensive care unit. Acta Neurochir. Wien. 1999;141:130308.

4. Suetens C., Latour K., Kärki T. et al. Prevalence of healthcare-associated infections, estimated incidence and composite antimicrobial resistance index in acute care hospitals and long-term care facilities: results from two European point prevalence surveys, 2016 to 2017. Euro Surveill. 2018;23(46):1800516. doi: 10.2807/1560-7917. ES.2018.23.46.1800516.

5. Rybkin I., Azizkhanian I., Gary J. et al. Unique Neurosurgical Morbidity and Mortality Conference Characteristics: A Comprehensive Literature Review of Neurosurgical Morbidity and Mortality Conference Practices with Proposed Recommendations. World Neurosurg. 2020;135:48-57. doi: 10.1016/j.wneu.2019.11.028.

6. Hammers R., Anzalone S., Sinacore J. et al. Neurosurgical mortality rates: what variables affect mortality within a single institution and within a national database? J Neurosurg. 2010;112(2):257-64. doi: 10.3171/2009.6.JNS081235.

7. Elsamadicy A.A., Sergesketter A., Sampson J.H. et al. Institutional Review of Mortality in 5434 Consecutive Neurosurgery Patients: Are We Improving? Neurosurgery, 2018; 6(83):1269-1276. doi: 10.1093/ neuros/nyx603.

8. World Health Organization. WHO Guidelines on hand hygiene in health care: first global patient safety challenge clean care is safer care. Geneva: WHO; 2009. Available on: http://apps.who.int/iris/ bitstream/10665/44102/1/9789241597906_eng.pdf.
9. Umscheid C.A., Mitchell M.D., Doshi J.A. et al. Estimating the proportion of healthcare-associated infections that are reasonably preventable and the related mortality and costs. Infect Control Hosp Epidemiol. 2011;32:101-114. doi: 10.1086/657912.

10. Raffaldi I., Scolfaro C., Pinon M. et al. Surveillance study of Healthcareassociated infections in a pediatric neurosurgery unit in Italy. Pediatr Neurosurg. 2011:47:26-25.

11. Horan T.C., Andrus M., Dudeck M.A. CDC/NHSN surveillance definition of health care-associated infection and criteria for specific types of infections in the acute care setting. Am J Infect Control. 2008;36(5):309332. doi:10.1016/j.ajic.2008.03.002.

12. Centers for Disease Control and Prevention (CDC): Surgical site infection (SSI) event. Available at: http://www.cdc.gov/nhsn/pdfs/ pscmanual/9pscssicurrent.pdf

13. Centers for Disease Control and Prevention (CDC): CDC/NHSN Surveillance Definitions for Specific Types of Infections. Available at: https://www. cdc.gov/nhsn/pdfs/pscmanual/17pscnosinfdef_current.pdf

14. BusI K.M. Healthcare-Associated Infections in the Neurocritical Care Unit. Curr Neurol Neurosci Rep. 2019;19:76. doi: 10.1007/s11910-019-0987-y.

15. Orsi G.B., Scorzolini L., Franchi C. et al. Hospital-acquired infection surveillance in a neurosurgical intensive care unit. J. Hosp. Infect. 2006;64:23-29. doi: 10.1016/j.jhin.2006.02.022.

16. Agarwal R., Mohapatra S., Rath G.P. et al. Active Surveillance of Health Care Associated Infections in Neurosurgical Patients. J Clin Diagn Res. 2017;11(7):DC01-DC04. doi: 10.7860/JCDR/2017/26681.10146.

17. Hopmans T.E., Blok H.E., Troelstra A. et al. Prevalence of hospitalacquired infections during successive surveillance surveys conducted at a university hospital in the Netherlands. Infect Control Hosp Epidemiol. 2007;28(4):459-65. doi: 10.1086/512640.

18. Hussein K., Bitterman R., Shofty B. et al. Management of postneurosurgical meningitis: narrative review. Clin Microbiol Infect. 2017;23(9):621-628. doi: 10.1016/j.cmi.2017.05.013.

19. Torres $S$. et al. Incidence of surgical site infection after craniotomy: comparison between three months and twelve months of epidemiological surveillance. Braz J Infect Dis 2018;22 (5):433-437. doi: 10.1016/j.bjid.2018.08.001.

20. Tae Seok Jeong, Gi Taek Yee. Prospective Multicenter Surveillance Study of Surgical Site Infection after Intracranial Procedures in Korea: A Preliminary Study. J Korean Neurosurg Soc. 2018;61 (5): 645-652. doi: 10.3340/jkns.2018.0021.

21. McClelland S. 3rd, Hall W.A. Postoperative central nervous system infection: incidence and associated factors in 2111 neurosurgical procedures. Clin Infect Dis. 2007;45(1):55-9. doi: 10.1086/518580.

22. Kołpa M., Wałaszek M., Różańska A. et al. Epidemiology of Surgical Site Infections and Non-Surgical Infections in Neurosurgical Polish Patients-Substantial Changes in 2003-2017. Int J Environ Res Public Health. 2019;16(6):911. doi:10.3390/ijerph16060911.

23. Wang J., Ji Y., Jiang L. et al. Analysis of factors influencing hospitalacquired infection in postoperative patients with intracranial aneurysm. BMC Neurol. 2019;19(1):332. doi:10.1186/s12883-019-1565-2.

We would like to thank all the nurses and physicians who contributed to the prevalence surveys and members of Ukrainian association of infection control and antimicrobial resistance for collected surveillance data from different Ukrainian Regions.

This work is a fragment of a research study of the Scientific Research Laboratory of Shupyk National Medical Academy 
of Postgraduate Education (Kyiv, Ukraine). Title: The scientific justification for measures to combat the resistance of microorganisms to antimicrobial drugs in Ukraine on the "One Health" approaches. State Registration Number: 0120U101440. Study period: 2020-2022. This work was funded by the Ministry of Health of Ukraine according to the plan of that research study. The authors did not receive any financial support from the manufacturers of medical instruments and drugs.

\section{ORCID and contributionship:}

Aidyn G. Salmanov: 0000-0002-4673-1154 A,C, D, E,F

Dmytro V. Shchehlov: 0000-0003-1465-8738 ${ }^{B, C, D, F}$

Oleh Svyrydiuk: 0000-0001-7455-0396 ${ }^{B, C, D, F}$

Ihor M. Bortnik: 0000-0001-8072-6570 B,C,D,F

Maryna Mamonova: 0000-0002-0697-4864 ${ }^{B, C, D, F}$

Yaroslav Kudelskyi: 0000-0002-4345-5959 B,C,D,F

Farida H. Rzayeva: 0000-0001-8481-7111 C,D,F

\section{Conflict of interest:}

The Authors declare no conflict of interest.

\section{CORRESPONDING AUTHOR}

Aidyn G. Salmanov

Shupyk National Healthcare University of Ukraine

9 Dorohozhytska St., 04112 Kyiv, Ukraine

tel: +380667997631

e-mail:mozsago@gmail.com

Received: 10.04.2021

Accepted: 29.07.2021

A - Work concept and design, B - Data collection and analysis, C - Responsibility for statistical analysis,

D-Writing the article, $\mathbf{E}$ - Critical review, $\mathbf{F}$ - Final approval of the article 